\section{Public Health} Genomics
Public Health Genomics 2012;15:327-334

DOI: $\underline{10.1159 / 000341889}$
Received: May 8, 2012

Accepted after revision: July 9, 2012

Published online: September 11, 2012

\title{
Public Health Action in Genomics Is Now Needed beyond Newborn Screening
}

\author{
M.S. Bowen K. Kolor W.D. Dotson R.M. Ned M.J. Khoury \\ Centers for Disease Control and Prevention, Department of Health and Human Services, Atlanta, Ga., USA
}

\section{Key Words}

Cascade screening • Evidenced-based recommendations • Health impact • Tier 1 genomics applications

\begin{abstract}
For decades, newborn screening was the only public health program in the US focused on reducing morbidity, mortality and disability in people affected by genetic conditions. The landscape has changed, however, as evidence-based recommendations are now available for several other genomic applications that can save lives now in the US. Many more such applications are expected to emerge in the next decade. An action plan, based on evidence, provides the impetus for a new paradigm for public health practice in genomics across the lifespan using established multilevel processes as a guide. These include policy interventions, education, clinical interventions, and surveillance. Applying what we know today in hereditary breast/ovarian cancer, Lynch syndrome and familial hypercholesterolemia has the potential to affect thousands of people in the US population every year. Enhanced partnerships between genetic and nongenetic providers of clinical medicine and public health are needed to overcome the challenges for implementing genomic medicine applications both now and in the future.
\end{abstract}

Copyright $\odot 2012$ S. Karger AG, Basel
(C) 2012 S. Karger AG, Basel

$1662-4246 / 12 / 0156-0327 \$ 38.00 / 0$

Fax +4161306 1234

E-Mail karger@karger.ch

www.karger.com
Accessible online at: www.karger.com/phg

\section{Background}

Advances in genomics and related fields created expectations for a flood of new health-related applications, such as tests and interventions that could reduce the burden of common complex diseases in populations. However, while there are an increasing number of genomic applications that are progressing from bench to bedside (a total of 419 were identified from horizon scanning on May 1, 2012), few have actually been widely adopted in clinical practice, mainly because of the insufficient evidence base to support their use [1].

While most emerging genomic applications will be implemented in a clinical health care setting, there remains a crucial role for state-based public health programs. Newborn screening (NBS), the first widely administered state-based public health program in the US aimed at reducing morbidity and mortality in people with certain genetic conditions through early diagnosis, began in 1963 as a means to find infants with phenylketonuria and has grown to become an integral component of public health practice [2]. At present, the Secretary's Advisory Committee on Heritable Disorders in Newborns and Children recommends 31 core conditions for NBS, many of which are single gene disorders [3]. NBS can identify about 12,500 infants every year who are in need of timely intervention to improve health outcomes [4]. A strong rationale for public health intervention ex-

Michael Scott Bowen

Centers for Disease Control and Prevention

1600 Clifton Rd, MS-61

Atlanta, GA 30333 (USA)

Tel. +1 404498 0068, E-Mail msb4@cdc.gov 
ists because many infants with these conditions would not otherwise be diagnosed by the clinical health care system alone in time for early and effective interventions to prevent mortality, morbidity and disability. While considered a traditional component of public health, NBS continues to adapt and improve and may benefit from next-generation sequencing or whole-genome sequencing in the near future.

We have now reached a point in the development of genomics such that new public health programs are needed for active interventions beyond NBS. These include an increasing number of conditions that are currently poorly ascertained by health care and for which evidencebased recommendations for improving health are already available.

To consider the readiness of genomic applications for practice, a useful framework for public health has been proposed by Khoury et al. [5]. The framework considers, in the context of intended use, a genomic application's analytic validity, clinical validity, clinical utility, balance of benefits and harms, and the existence of an evidencebased recommendation. The tiers of the classification system are characterized as follows:

Tier 1 applications have demonstrated analytic validity, clinical validity, clinical utility, and there are evidenced-based guidelines encouraging their use.

Tier 2 applications have demonstrated analytic and clinical validity, hold promise for demonstrating clinical utility (e.g. when benefits in terms of patient outcomes are highly plausible, and well-designed trials with appropriately selected endpoints are known to be planned or in progress), but no evidence-based guidelines recommending clinical use. Such applications may provide information for informed decision-making.

Tier 3 applications have not yet demonstrated adequate analytic validity, clinical validity or clinical utility, or have demonstrated evidence of harms. The use of such applications should be discouraged in practice, but may be considered for use in research in some instances.

In this commentary, we focus entirely on tier 1 applications. In table 1 below and in the Appendix, we list details on 3 such genomic applications. Several categories of information are compiled for each, including: public health burden and context, the existence of an evidencebased recommendation, intended use; status of current practice, potential impact, and evidence of cost effectiveness. The CDC Office of Public Health Genomics website (http://www.cdc.gov/genomics/) maintains an updated list of tier 1-3 genomic applications (http://www.cdc.gov/ genomics/gtesting/tier.htm).

\section{Tier 1 Genomic Applications: Opportunities and Challenges for Public Health Interventions to Save Lives}

In 2005, the US Preventive Services Task Force (USPSTF) recommended offering genetic counseling for the use of $B R C A 1 / 2$ testing in women with a strong family history of breast and/or ovarian cancer [6]. Two other genomic applications have since met the tier 1 criteria through evidence review and recommendations by independent, evidence-based panels. In 2008, the UK's National Institute for Health and Clinical Excellence recommended cascade screening in relatives of patients with familial hypercholesterolemia (FH) to prevent cardiovascular morbidity and mortality among affected relatives [7]. In 2009, the US-based Evaluation of Genomic Applications in Practice and Prevention Working Group recommended genetic testing for Lynch syndrome (LS) among all newly diagnosed colorectal cancer (CRC) cases to reduce morbidity and mortality in relatives through testing and surveillance as appropriate [8]. These 3 recommendations concern autosomal dominant disorders with health implications throughout life and use family health history information to identify those at risk in order to cascade from an affected person to the rest of the family. Also, one common feature among all 3 is that the health care system alone has not optimally identified people with these diseases to benefit their relatives (see below and table 1). A notable difference among the 3 is ascertainment in that implementation of the USPSTF BRCA recommendation begins with unaffected women in the general population, whereas the others begin with people affected by the disease of interest. Public health action, based on these evidence-based recommendations to leverage family history and/or cascade screening with policy changes, provides the immediate potential to reach thousands of people in the US each year. Two of these applications, BRCA1/2 and LS, are now part of the Healthy People 2020 objectives from the US Department of Health and Human Services [9].

The theoretical reach for public health genomic interventions beyond NBS must be considered in the light of many challenges and limitations, however. Implementation will be complex in the US because it must occur within a health care system that, unlike many European countries and Canada, is not interconnected or centrally coordinated, and in which exists widely varying coverage depending on individual insurance plans and resources. This is a challenge not only because there is a wide disparity in health care coverage for non-NBS tier 1 applications, 
Table 1. Selected tier 1 emerging genetic and genomic applications, May 2012

\begin{tabular}{|c|c|c|c|c|c|c|c|}
\hline $\begin{array}{l}\text { Issue/ } \\
\text { condition }\end{array}$ & Tests & $\begin{array}{l}\text { Public health context } \\
\text { and burden }\end{array}$ & $\begin{array}{l}\text { Evidence-based } \\
\text { recommenda- } \\
\text { tions }\end{array}$ & Intended use & $\begin{array}{l}\text { Status of } \\
\text { current practice }\end{array}$ & Potential impact & Cost effective? \\
\hline $\begin{array}{l}\text { NBS } \\
\text { (including } \\
\text { genetic } \\
\text { conditions) }\end{array}$ & $\begin{array}{l}\text { multiple } \\
\text { molecular, } \\
\text { biochemical, } \\
\text { and other } \\
\text { tests }\end{array}$ & $\begin{array}{l}4 \text { million US newborns } \\
\text { are screened each year; } \\
12,500 \text { are diagnosed } \\
\text { with one or more core } \\
\text { conditions [4] }\end{array}$ & $\begin{array}{l}\text { SACHDNC } \\
\text { recommends a } \\
\text { panel of } 31 \text { core } \\
\text { conditions [3] }\end{array}$ & $\begin{array}{l}\text { preventing morbidity, } \\
\text { mortality and disability } \\
\text { in newborns and } \\
\text { infants, with lifelong } \\
\text { impact }\end{array}$ & $\begin{array}{l}\text { panels vary } \\
\text { among states }\end{array}$ & $\begin{array}{l}12,500 \text { children with } \\
\text { positive results acted upon } \\
\text { annually as currently } \\
\text { practiced [4] }\end{array}$ & $\begin{array}{l}\text { yes } \\
{[25-28]}\end{array}$ \\
\hline $\begin{array}{l}\text { Hereditary } \\
\text { breast/ } \\
\text { ovarian } \\
\text { cancer }\end{array}$ & $\begin{array}{l}\text { BRCA } \\
\text { analysis }\end{array}$ & $\begin{array}{l}2-7 \% \text { of breast cancer } \\
(\sim 10,000 \text { cases/year in } \\
\text { the US }) ; 10-15 \% \text { of } \\
\text { ovarian cancer }(\sim 2,700 \\
\text { cases/year in the US }) \\
\text { associated with BRCA } \\
\text { mutations }[15-17]\end{array}$ & $\begin{array}{l}\text { USPSTF } 2005 \\
\text { recommen- } \\
\text { dation [6] }\end{array}$ & $\begin{array}{l}\text { for women without } \\
\text { breast/ovarian cancer, } \\
\text { but at high risk because } \\
\text { of family history [6] }\end{array}$ & $\begin{array}{l}\text { underutilization } \\
\text { [9]; disparities } \\
\text { [19]; Affordable } \\
\text { Care Act- } \\
\text { covered } \\
\text { preventive } \\
\text { service }\end{array}$ & $\begin{array}{l}\text { prophylactic surgery can } \\
\text { reduce cancer risk by } 85 \% \\
\text { [6]; surveillance, chemopre- } \\
\text { vention, and risk avoidance } \\
\text { options are available, but } \\
\text { with limited high-quality } \\
\text { data on effectiveness [18] }\end{array}$ & $\begin{array}{l}\text { some evidence } \\
\text { for targeting } \\
\text { genetic servic- } \\
\text { es and preven- } \\
\text { tive strategies } \\
{[29-31]}\end{array}$ \\
\hline LS & $\begin{array}{l}\text { CRC tumor } \\
\text { testing; DNA } \\
\text { muta- } \\
\text { tion analysis } \\
\text { in relatives }\end{array}$ & $\begin{array}{l}\sim 143,000 \text { cases of CRC } \\
\text { diagnosed/year in the US, } \\
\text { including } \sim 4,200 \text { due to } \\
\text { LS [10]; as many as } 1 \text { in } \\
370 \text { people in the US } \\
\text { may have LS }[20]\end{array}$ & $\begin{array}{l}\text { EGAPP } 2009 \\
\text { recommendation: } \\
\text { offer genetic } \\
\text { testing for LS to } \\
\text { all persons with } \\
\text { newly diagnosed } \\
\text { CRC [8] }\end{array}$ & $\begin{array}{l}\text { test new cases of CRC } \\
\text { for LS and cascade } \\
\text { screening for family } \\
\text { members [8] }\end{array}$ & $\begin{array}{l}\text { very little } \\
\text { implemen- } \\
\text { tation by } \\
\text { health plans }\end{array}$ & $\begin{array}{l}>98 \% \text { of people with LS are } \\
\text { undiagnosed [20]; initial } \\
\text { cascade screening could } \\
\text { prevent } \sim 4,800 \text { CRC cases } \\
\text { over the lifetime of relatives }\end{array}$ & $\begin{array}{l}\text { yes, ICER } \\
\leq \text { USD 25,000 } \\
\text { for least costly } \\
\text { testing ap- } \\
\text { proach [21] }\end{array}$ \\
\hline $\mathrm{FH}$ & $\begin{array}{l}\text { cholesterol } \\
\text { test w/wo } \\
\text { genetic } \\
\text { testing }\end{array}$ & $\begin{array}{l}\sim 7.9 \text { million people in } \\
\text { the US have had a heart } \\
\text { attack; FH affects } \\
\sim 600,000 \text { people in the } \\
\text { US [22] }\end{array}$ & $\begin{array}{l}\text { NICE } 2008 \\
\text { recommen- } \\
\text { dation [7] }\end{array}$ & $\begin{array}{l}\text { initiate cascade screen- } \\
\text { ing from identified FH } \\
\text { cases (screen at least } \\
\text { first- and second- } \\
\text { degree relatives) [7] }\end{array}$ & $\begin{array}{l}\geq 75 \% \text { of } \mathrm{FH} \\
\text { cases are not } \\
\text { diagnosed }[22]\end{array}$ & $\begin{array}{l}\text { potentially prevent } \\
\text { thousands of heart attacks/ } \\
\text { year; prevent }>110,000 \\
\text { heart attacks over lifetimes } \\
\text { of people with FH }\end{array}$ & yes [22] \\
\hline
\end{tabular}

Tier 1 applications have demonstrated analytic and clinical validity, and clinical utility; there are evidenced-based guidelines encouraging use. Surveillance includes use of existing surveillance systems such as BRFSS and registries to monitor appropriate use and disparities. Cascade screening involves identifying at-risk family members through an affected individual.

SACHDNC = Secretary's Advisory Committee on Heritable Disorders in Newborns and Children; USPSTF = U.S. Preventive Services Task Force; EGAPP = Evaluation of Genomic Applications in Practice and Prevention; NICE = National Institute for Health and Clinical Excellence (in the UK); ICER = incremental cost-effectiveness ratio; NBS = newborn screening; LS = Lynch syndrome; FH = familial hypercholesterolemia.

but also because cascade screening, which can be helpful if not critical for all 3 diseases, must identify and provide interventions to relatives who are likely not in the same payer network and whose health records are not linked. Also, there are privacy concerns when cascade screening is used to contact the relatives of a patient who has already been diagnosed or is known to have a specific genetic condition. Unlike the case with NBS, there are no universal screening programs in the US to identify people recommended for these applications; nor at present can the case be made for population screening of these applications in the US in the absence of pilot or demonstration programs to show scalability and effectiveness in the real world [10]. Further, many who should have the test may not have the resources to pay for either the genetic testing or the followup treatments or screenings which might be indicated. Unlike NBS, there are no mandated statewide public health systems in place to implement and measure non-
NBS test use or to follow up on the results. Finally, fundamental resistance to system change can only be overcome with effective communication of the rewards for taking action, especially to budget and policy decision makers.

While these challenges are considerable, there are some impactful tier 1 opportunities that can be taken advantage of now for a relatively low amount of public health investment to promote and monitor ascertainment for tier 1 genomic applications by health care. Regardless, it is clear that successful ascertainment for tier 1 genomic applications beyond NBS in the US will require nontraditional partnerships between state public health departments and numerous health care payers and providers. A brief review of the 3 example conditions and the respective potential population impact of public health implementation strategies that complement clinical care are shown in table 1 and in the Appendix. 


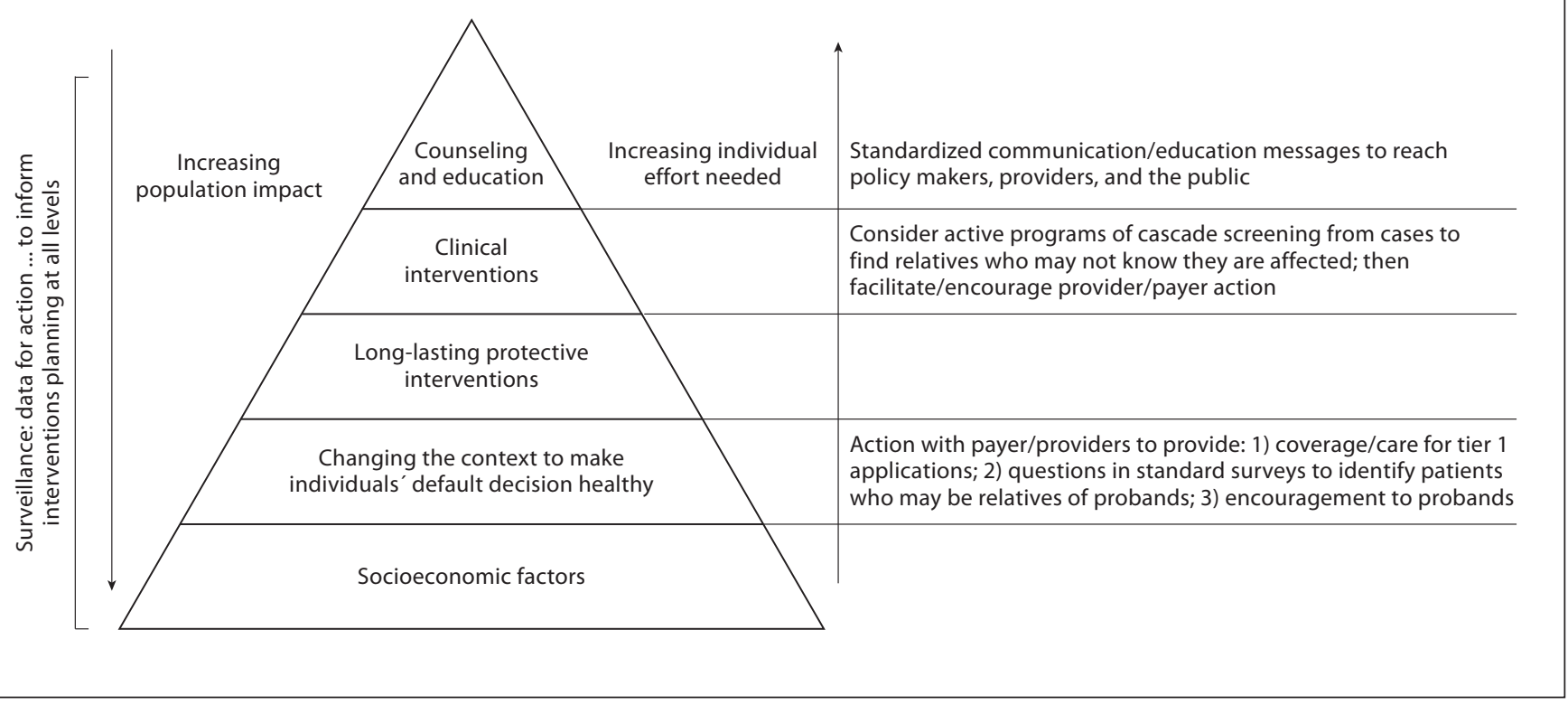

Fig. 1. Health impact pyramid applied to tier 1 genomics applications. Original pyramid by Frieden [12].

\section{What Can Public Health Do Now? - Multilevel Interventions}

To tackle these substantial challenges, it is useful to consider multilevel public health approaches, using the core public health functions of assessment, policy development and assurance $[5,11]$. Dr. Thomas Frieden, the current director of the $\mathrm{CDC}$, has proposed a health impact pyramid to assess the potential impact of different types of interventions [12]. This was recently discussed in the context of human genomic applications [5]. The 5-tier pyramid, as shown on the left side of figure 1 , describes the different types of public health interventions, with the potential impact being greater the closer the intervention type is to the base. While there is a place for public health efforts at all levels of the pyramid, challenges and available resources pragmatically dictate that effort should be placed as low on the pyramid as is feasible. In the case of tier 1 genomic applications, this means that, at present, much of the public health focus should be placed specifically on the level 'changing the context to make default individual's decisions healthy'; in other words: policy interventions.

\section{Policy Interventions}

Despite the inherent challenges of coordinating with multiple unconnected payer and provider networks with- in the US health care system, strategies to influence policy within states can be effective. Consider the highly successful work of the model genomics program started in Michigan, which worked closely with health care partners to extend health insurance coverage consistent with the USPSTF recommendation for BRCA genetic counseling and evaluation to over 6.6 million additional people within its borders by 2011 [13]. Similar work aimed at state and national reimbursement guidelines is also critical. As shown in figure 1, other strategies could include leveraging such partnerships to add questions to standard payer/provider data collection instruments in an attempt to identify patients who, by virtue of being relatives of probands, might be at risk and in need of further testing. Health care networks could also institute protocols including prepared letters/forms and policies to encourage affected persons within their system to reach out to their relatives to seek screening, even those who might not be under the same coverage system. Inclusion of family health history and other genomic information in electronic medical records standards is also important. Furthermore, policy changes aimed at incorporating relevant data fields which identify tier 1 condition status within cancer registries might be effective for programmatic linkage efforts and for surveillance and epidemiologic purposes. 


\section{Education}

While at the top of the pyramid in terms of overall effectiveness, standard education/communication instruments are needed as part of the effort to provide timely information to policy makers, to inform the public, providers, and other stakeholders about the issues, and to motivate individual and collaborative action. The development of standard, vetted instruments and messages that can be adapted by states will prevent duplication of effort and lower the costs of action in this area. Further, genomic tier 1 core competencies for health care providers at various levels, including those for primary care providers and oncologists, need to be developed and facilitated.

\section{Surveillance}

Public health surveillance is needed to collect data within populations concerning the need for, appropriate usage of, and impact of tier 1 applications. In order to maximize the ability to compare data, assess disparities and progress, and limit the costs of these efforts, it is useful for states to measure the same data elements. For example, common modules developed via state partnership for use through the Behavioral Risk Factor Surveillance System (BRFSS) and other surveillance approaches would offer many advantages. The BRFSS is a state-based telephone health survey system that collects information on health risk behaviors, preventive health practices and health care access primarily related to chronic disease and injury. For many states, the BRFSS is the only available source of timely, accurate data on health-related behaviors [14].

In the context of cancer, all states have cancer registries that collect information on the occurrence of cancer. These registries can be used to integrate information on hereditary breast, ovarian and CRC to track progress in implementation of tier 1 genomic applications [10].

\section{Active Clinical Intervention Programs}

Cascade screening programs for family members of affected persons identified through health care networks or registries should be considered. Electronic medical records could be used to help standardize/automate systematic identification methods. Pilot approaches should be developed and tested which are designed for the US health care system, and accountable care or integrated health care organizations should be considered for these early efforts. Projects for LS and CRC conducted at Ohio State University already provide some lessons learned. Ohio State University was among the first centers to demonstrate the feasibility of screening all newly diagnosed CRC cases for LS [10]. Experience gained from such initial efforts can be exported through shared protocols. In the future, public health can take active roles in cascade screening including assistance with the identification of affected family members using skills developed from other areas. For instance, state and local health departments can use their extensive experience - previously gained from outbreak investigations and sexually transmitted diseases tracking to reach people at risk and in need of intervention. However, in this case, there would be a genetic link from the patient case to others at risk and not simply a common exposure. Ethical, legal and social implications regarding the unique nature of tier 1 programs would have to be considered and addressed appropriately at all times.

\section{Public Health-Health Care Collaboration through a}

National State/Federal/Stakeholder Partnership

To accomplish all of these goals, a national coalition of public health agencies and health care providers/payers and other stakeholders is needed. The mutual support and economies of scale provided by an active and cohesive partnership may be the best means of collectively navigating the unusual challenges of these applications for effectively reaching thousands of people with tier 1 conditions. Furthermore, strong collaborations are needed to coordinate the collective resources needed for successful implementation.

\section{Next Steps for State Public Health Departments to Consider}

Among, the strategies above, there are several action steps that state public health departments can take now for integrating tier 1 genomic applications beyond NBS into their programs, including: (1) review and build on the previous success of the model state public health genomics programs (the Michigan program mentioned earlier as just one example [13]); (2) participate in the development of, and then share standardized protocols for, engaging payer/provider partners in states; (3) participate in the development and distribution of standardized and vetted communication/education materials on tier 1 applications for the public, payers, providers and policy makers; (4) participate in the development of a standard BRFSS module that can be used in every state, and through collaboration with partners, identify opportunities with provider and payer data systems to measure progress; 
(5) participate in the building of a federal or nationwide state action group for tier 1 genomic application implementation, with the ultimate goal of involving all states; (6) conduct pilot projects in a few states to examine the feasibility, scalability and cost-effectiveness of implementing active cascade screening programs; (7) build successful relationships with payers, providers, advocacy groups, and other stakeholders within the state to implement policy interventions, set goals and monitor results; (8) explore opportunities for funding additional tier 1 application intervention programs/efforts through federal grants and nongovernmental organizations; (9) stay abreast of changes in the field as emerging genomic applications with sufficient evidence for implementation become available.

\section{Concluding Remarks}

Because of hype and disappointment regarding the availability of genomic applications with sufficient evidence to integrate into practice, many policy makers, providers, payers, and patients may have taken an understandable 'wake me when we arrive' approach to the field. However, both medicine and public health can act now to implement an increasing number of tier 1 genomic applications. Just as the first NBS efforts overcame substantial obstacles, reaching full impact with the 3 genomic testing applications requires that significant challenges be addressed. However, there are several, clear next steps that state public health departments can now take collectively to reap 'low-hanging fruit' for each of the 3 tier 1 applications discussed. Most of these immediate opportunities involve policy interventions and require partnerships with clinical health care providers and payers. These 'trail blazing' implementation efforts, including those already underway by model programs like Michigan, will provide valuable experience, as additional tier 1 applications will emerge in coming years. Next generation tools will likely be based on newer molecular technology but will also focus on common variants for common chronic diseases. Furthermore, it is likely that cascade screening methodology will remain an important strategy for implementing these future applications.

Today, public health operates in a world of rapidly changing technology, ambitious impact goals and limited resources. In this environment, past approaches may not be good enough, and the value of emerging tools, including genomic applications, should continually be assessed in an effort to improve the results of all traditional pro- grams. Public health should continue to pursue new evidence based technologies and methods to improve the reach and quality of NBS. Meanwhile, tier 1 applications offer the potential to expand on the success of established state-based genetics and chronic disease programs to impact even more lives.

\section{Disclaimer}

The opinions expressed in this paper are those of the authors and do not necessarily represent the views of the Centers for Disease Control and Prevention.

\section{Appendix}

BRCA1/2: Reducing the Burden of Breast and Ovarian Cancer among Women at Increased Hereditary Risk

About $2-7 \%$ of breast cancer and $10-15 \%$ of ovarian cancer are due to inherited genetic changes in the BRCA1 or BRCA2 genes [15]. These percentages translate to approximately 10,000 cases of breast cancer and 2,700 cases of ovarian cancer that are associated with BRCA1/2 mutations each year in the US, based on 2012 estimates for new cases of breast and ovarian cancer [16, 17]. For women with a $B R C A 1 / 2$ mutation that is clinically important, the probability of developing breast or ovarian cancer by the age of 70 is estimated to be between $35-84 \%$ (breast) and $10-50 \%$ (ovarian) [6].

The USPSTF recommends that women with certain high risk patterns of family health history of breast and ovarian cancer associated with BRCA1/2 mutations be referred for genetic counseling and evaluation by suitably trained health care providers to promote informed decision-making about genetic testing [6]. The USPSTF found fair evidence that for women with BRCA1/2 mutations, prophylactic bilateral mastectomy reduces breast cancer risk by $85 \%$ or more, and prophylactic oophorectomy reduces ovarian cancer risk by $85 \%$ or more and breast cancer risk by $53 \%$ or more [6]. Other interventions might include intensive screening, chemoprevention, risk avoidance, or a combination of these; however, high-quality data on the effectiveness of these interventions may be limited [18]. There is evidence that there is both underutilization [9] and disparities in the availability and/or uptake [19] of BRCA genetic services.

\section{LS: Preventing CRC in Families at Increased Hereditary Risk} Is Cost Effective

LS is the most common cause of inherited CRC, and about $3 \%$ of CRC cases are due to this condition. Mutations in mismatch repair (MMR) genes confer a lifetime CRC risk of $54-74 \%$ in males and $30-52 \%$ in females, and screening colonoscopy at $1-$ to 3 -year intervals among people with LS can reduce risk by about $60 \%$. Based on the number of CRC cases diagnosed in the US in 2007 alone (143,000), an estimated 4,200 cases were due to LS [10]. LS may affect as many as 800,000 people in the US, and an estimated $98 \%$ of these people may be undiagnosed [20].

The Evaluation of Genomic Applications in Practice and Prevention recommends that genetic testing for LS be offered to all 
persons with newly diagnosed CRC and that cascade screening then be used to reach relatives, creating a unique opportunity to prevent CRC, through increased surveillance where indicated, in thousands of people using relatively inexpensive tests $[8,10]$. Furthermore, an analysis conducted in 2009 found that this cascading approach is cost effective - being at least comparable with other preventive services [21].

\section{FH: Preventing Cardiovascular Disease in Families at} Increased Hereditary Risk

FH is a disorder characterized by high levels of low-density lipoprotein cholesterol in the blood, which results in increased risks of premature coronary heart disease (CHD) and death. In fact, there is a cumulative risk of CHD that is greater than $50 \%$ in men by the age of 50 and is at least $30 \%$ in women by the age of 60 for those with heterozygous FH (those who have inherited one disease-causing mutation) and includes a 100-fold increase in mortality from CHD for people under the age of 40 [22, 23]. FH is one of the most common inherited disorders, with a worldwide prevalence of 1 in 500 (which translates into approximately 13 million persons worldwide and 600,000 people in the US af- fected with $\mathrm{FH}$ ) [22]. It is estimated that at least $75 \%$ of $\mathrm{FH}$ cases are not diagnosed, though many could be found efficiently since $50 \%$ of first degree relatives are also affected [22]. Statin treatment to lower serum low-density lipoprotein cholesterol levels is highly effective and has been shown to reduce morbidity and mortality, making it important to identify affected persons early [22]. Consistent drug compliance is important in cases of $\mathrm{FH}$, since dietary and other behavioral interventions are not enough to treat the condition $[22,24]$. If people in the US with undiagnosed FH could be identified and provided a cholesterol-reducing medication, thousands of heart attacks each year could be prevented (see table 1).

The 2008 National Institute for Health and Clinical Excellence guideline recommends that cascade screening be initiated from identified FH cases in the UK to include at least first- and seconddegree relatives [7]. There is a need to assess the potential development of evidence-based FH recommendations designed specifically for the US health care system. Regardless, there are opportunities to apply what has been learned in the UK to the US environment now.

\section{References}

1 GAPP Knowledge Base. http://www.hugenavigator.net/GAPPKB/ (accessed February 29, 2012).

2 The National Human Genome Research Institute: Appendix 5. The history of newborn phenylketonuria screening in the U.S. http:// biotech.law.lsu.edu/research/fed/tfgt/appendix5.htm (accessed February 29, 2012).

3 Department of Health and Human Services: Secretary's Advisory Committee on Heritable Disorders in Newborns and Children. 2011. http://www.hrsa.gov/advisorycommittees/mchbadvisory/heritabledisorders/ recommendedpanel/ (accessed February 29, 2012).

4 Howell RR: Current practices and expansion of newborn screening. 2011. http://www.cdc. gov/about/grand-rounds/archives/2011/ pdfs/GREHRAllFINAL18AUG2011.pdf (accessed February 29, 2012).

$\checkmark 5$ Khoury MJ, Bowen MS, Burke W, Coates RJ, Dowling NF, Evans JP, Reyes M, St Pierre J: Current priorities for public health practice in addressing the role of human genomics in improving population health. Am J Prev Med 2011;40:486-493.

$\checkmark 6$ U.S. Preventive Services Task Force: Genetic risk assessment and BRCA mutation testing for breast and ovarian cancer susceptibility: recommendation statement. Ann Intern Med 2005;143:355-361.

7 National Institute for Help and Clinical Excellence: CG71 familial hypercholesterolaemia: NICE guideline. 2010. http://guidance. nice.org.uk/CG71/NICEGuidance/pdf/ English (accessed February 29, 2012).
-8 Evaluation of Genomic Applications in Practice and Prevention (EGAPP) Working Group: Recommendations from the EGAPP Working Group: genetic testing strategies in newly diagnosed individuals with colorectal cancer aimed at reducing morbidity and mortality from Lynch syndrome in relatives. Genet Med 2009;11:35-41.

9 Healthy People.gov: 2020 Topics \& Objectives, Genomics. 2012. http://www.healthypeople.gov/2020/topicsobjectives2020/objectiveslist.aspx?topicId = 15 (accessed February 29, 2012).

10 Bellcross C, Bedrosian SR, Daniels E, Duquette D, Hampel H, Jasperson K, Joseph DA, Kaye C, Lubin I, Meyer LJ, Reyes M, Scheuner MT, Schully SD, Senter L, Stewart SL, St Pierre J, Westman J, Wise P, Yang VW, Khoury MJ: Implementing screening for Lynch syndrome among patients with newly diagnosed colorectal cancer: summary of a public health/clinical collaborative meeting. Genet Med 2012;14:152-162.

11 Khoury MJ: From genes to public health: the applications of genetic technology in disease prevention. Genetics Working Group. Am J Public Health 1996;86:1717-1722.

12 Frieden TR: A framework for public health action: the health impact pyramid. Am J Public Health 2010;100:590-595.

13 Duquette D, Lewis K, McLosky J, Bach J: Using core public health functions to promote $B R C A$ best practices among health plans. Public Health Genomics 2012;15:92-97.

14 http://intranet.cdc.gov/osels/phspo/bc/bc_ registry_profiles/Profile_Behavioral_Risk_ Factor_Surveillance_System_BRFSS.pdf (accessed February 29, 2012).
15 Bellcross CA, Kolor K, Goddard KA, Coates RJ, Reyes M, Khoury MJ: Awareness and utilization of BRCA1/2 testing among U.S. primary care physicians. Am J Prev Med 2011; 40:61-66.

16 National Cancer Institute: Breast Cancer. 2012. http://www.cancer.gov/cancertopics/ types/breast (accessed February 29, 2012).

17 National Cancer Institute: Ovarian Cancer. 2012. http://www.cancer.gov/cancertopics/ types/ovarian (accessed February 29, 2012).

18 National Cancer Institute: BRCA1 and BRCA2: Cancer Risk and Genetic Testing. 2009. http://www.cancer.gov/cancertopics/ factsheet/Risk/BRCA\#r4 (accessed February 29, 2012).

19 Hall MJ, Olopade OI: Disparities in genetic testing: thinking outside the $B R C A$ box. J Clin Oncol 2006;24:2197-2203.

20 Hampel H, de la Chapelle A: The search for unaffected individuals with Lynch syndrome: do the ends justify the means? Cancer Prev Res (Phila) 2011;4:1-5.

21 Mvundura M, Grosse SD, Hampel H, Palomaki GE: The cost-effectiveness of genetic testing strategies for Lynch syndrome among newly diagnosed patients with colorectal cancer. Genet Med 2010;12:93-104.

22 Ned RM, Sijbrands EJ: Cascade screening for familial hypercholesterolemia (FH). PLoS Curr 2011;3:RRN1238.

23 Risk of fatal coronary heart disease in familial hypercholesterolemia. Scientific Steering Committee on behalf of the Simon Broome Register Group. BMJ 1991;303:893-896. 
-24 Hunt SC, Gwinn M, Adams T: Family history assessment: strategies for prevention of cardiovascular disease. Am J Prev Med 2003; 24:136-142.

25 Grosse SD, Van Vliet G: Prevention of intellectual disability through screening for congenital hypothyroidism: how much and at what level? Arch Dis Child 2011;96:374-379.

-26 Centers for Disease Control and Prevention: Economic costs associated with mental retardation, cerebral palsy, hearing loss, and vision impairment - United States, 2003. MMWR Morb Mortal Wkly Rep 2004;53: $57-59$.
27 Grosse SD: How much does IQ raise earnings? Implications for regulatory impact analyses. AERE NL 2007;27:17-21.

28 Grosse SD: Education cost savings from early detection of hearing loss: new findings. Volta V 2007; 14:38-40.

29 Tengs TO, Berry DA: The cost effectiveness of testing for the BRCA1 and BRCA2 breastovarian cancer susceptibility genes: a decision analysis. Dis Manage Clin Outcomes 2000;2:15-24.
30 Balmaña J, Sanz J, Bonfill X, Casado A, Rué M, Gich I, Díez O, Sabaté JM, Baiget M, Alonso MC: Genetic counseling program in familial breast cancer: analysis of its effectiveness, cost and cost-effectiveness ratio. Int J Cancer 2004;112:647-652.

31 Anderson K, Jacobson JS, Heitjan DF, Zivin JG, Hershman D, Neugut AI, Grann VR: Cost-effectiveness of preventive strategies for women with a $B R C A 1$ or a BRCA2 mutation. Ann Intern Med 2006;144:397-406. 